\title{
Public Hospital Quality Assessment. Evidence from Greek Health Setting Using SERVQUAL Model
}

\author{
Aspasia Goula ${ }^{1, *}$, Maria-Aggeliki Stamouli ${ }^{1}{ }^{\circledR}$, Maria Alexandridou ${ }^{1}$, Lemonia Vorreakou ${ }^{1}$, \\ Aristeidis Galanakis ${ }^{1}$, Georgios Theodorou ${ }^{1}$, Emmanouil Stauropoulos ${ }^{1}$, Martha Kelesi ${ }^{2}$ and Evridiki Kaba ${ }^{2}$ (D) \\ 1 Master of Health and Social Care Management, Department of Business Administration, School of \\ Administrative, Economics and Social Sciences. University of West Attica, 12243 Athens, Greece; \\ mstamouli@yahoo.com (M.-A.S.); m.alexadridou@gmail.com (M.A.); lvorreak@gmail.com (L.V.); \\ aristeidhsgal@hotmail.com (A.G.); theodorougeorgios@gmail.com (G.T.); manosfed1326@hotmail.gr (E.S.) \\ 2 Department of Nursing, School of Health and Care Sciences, University of West Attica, 12243 Athens, Greece \\ mkel@uniwa.gr (M.K.); ekaba@uniwa.gr (E.K.) \\ * Correspondence: agoula@uniwa.gr
}

check for updates

Citation: Goula, A.; Stamouli, M.-A.; Alexandridou, M.; Vorreakou, L.;

Galanakis, A.; Theodorou, G.; Stauropoulos, E.; Kelesi, M.; Kaba, E. Public Hospital Quality Assessment. Evidence from Greek Health Setting Using SERVQUAL Model. Int. J. Environ. Res. Public Health 2021, 18, 3418. https://doi.org/10.3390/ ijerph18073418

Academic Editor: Paul B. Tchounwou

Received: 8 March 2021

Accepted: 23 March 2021

Published: 25 March 2021

Publisher's Note: MDPI stays neutral with regard to jurisdictional claims in published maps and institutional affiliations.

Copyright: (C) 2021 by the authors Licensee MDPI, Basel, Switzerland. This article is an open access article distributed under the terms and conditions of the Creative Commons Attribution (CC BY) license (https:/ / creativecommons.org/licenses/by/ $4.0 /)$.

\begin{abstract}
Background: Health care service quality has been equated with preparedness to provide, accessibility, suitability, adequacy, friendliness and ongoing support and has been connected to service excellence. The main aim of this study was to investigate patients' perceptions and expectations regarding the quality of health services. (2) Materials and Methods: A cross-sectional analysis was carried out in 5 public general hospitals and convenience sampling was used as the sampling technique. Questionnaires were distributed to inpatients and outpatients and 700 valid questionnaires were returned. The SERVQUAL questionnaire was used for data collection in this survey. (3) Results: Overall, in this study, it became apparent that patients' expectations as regarding the quality of the provided services were not met. All of the five quality dimensions had a negative gap between patients' expectations and perceptions. (4) Conclusions: The findings suggested that hospital managers and health care professionals should be interested about patient expectations and subsequently they should search out ways and means to meet them. Open communication with patients, individualized attention, as well as responsiveness to their requirements, polite behavior, trustful atmosphere across the hospital and better physical facilities are the key elements that determine the patient's judgment about quality.
\end{abstract}

Keywords: hospital quality; public hospitals; SERVQUAL model; patient expectations; patient perceptions

\section{Introduction}

The quality of services and its management in the modern public health administration has been the priority of reforms in many developed countries over the last few decades. Many measures have been partially or fully implemented in the Greek public health care system, including hospital mergers, decreasing the number of beds in clinics and specialist units, and changing the hospital payment system. The content and reform process was essentially technocratic/managerial in nature, with little respect for the health system's overall functioning and the needs of the patients [1].

Greece, over the 2008-2018 period, was under an economic crisis. As a result, the health system was underfunded. The public expenditure on health did not exceed $5 \%$ of the GDP, a percentage that was significantly lower than that of other developed countries [2]. The economic crisis had made more apparent the need for drastic reforms of the Greek health care system, so that it could equitably and universally provide high-quality services. Unfortunately, after budget reductions were made, the shares of government spending by health care function remained largely unchanged. The Greek health care system is strongly centred in hospitals and the primary care system has not been developed fully [1]. As a 
result, the inpatient care in 2018 was in the top area of health expenditure (44\%) which is the highest proportion in the EU27 (30\%) [3,4]. However, Greece is among the OECD countries with the lowest overall response rate for both inpatient and outpatient services $[5,6]$.

Eurobarometer studies suggest a high degree of patient dissatisfaction with Greece's quality of health care. In the 2014 survey, only 26 percent of respondents in Greece assessed the country's quality of hospital care as good, while 78 percent thought that the health of hospitalized patients may have "deteriorated" [7,8].

\section{Health Services Quality}

The term quality is easy to pronounce but it is very difficult to define precisely [9]. The American Society for Quality Control defines quality as "the totality of features and characteristics of a product (or service) that bears on its ability to satisfy stated or implied needs" [10].

Service quality has been equated with preparedness to provide, accessibility, suitability, adequacy, friendliness and ongoing support [10] and has been connected to service excellence, differentiation, competitive characteristics, and is extremely important for customer loyalty and retention [11-14].

Compared to the quality of products, the quality of services is more difficult for customers to determine, as both the results obtained (technical quality) and the service delivery process (functional quality) are evaluated [15]. According to Parasuraman, Berry and Zeithaml [16]: "unlike good quality, service quality is an abstract and elusive construct because of three features unique to services: intangibility, heterogeneity and inseparability of production and consumption". Therefore, an effective approach to assess quality is to evaluate the perceptions of customers about quality. Kano et al. [17] were the first to define product/service characteristics by taking into account their ability to establish customer satisfaction.

Concerning health service quality, the main difference between health services and other services is that they are based on patients' needs and not on customers' desires [18]. As a result, assessing quality in the health-care industry is becoming more complex. In addition, it is provided in a unique manner. Professionals offer health-care services, but there is frequently no visible result. In addition, as Taner and Antony stated, patients are quite unique as "customers" due to their low expertise and asymmetry of knowledge in comparison with health care professionals [6]. Patients are not skilled and do not have the needed knowledge to diagnose and treat [19].

The Institute of Medicine included patient satisfaction as an important element of health care outcomes in defining the dimensions of quality. In particular, it mentioned that "quality of care is the degree to which health services for individuals and populations increase the likelihood of desired health outcomes and are consistent with current professional knowledge" [20].

Since 1900, the notion of patient satisfaction has been an area of scientific study. The key emphasis at the beginning of modern medical science was to cure the patient or alleviate his or her suffering [21]. However, a new idea was introduced to the scientific community at the beginning of the 20th century that involved the assessment not only of the outcome of the illness, but also of the treatment provided [22,23].

Donadebian introduced a new dimension to the definition of patient satisfaction by connecting patient satisfaction to the quality of the health services offered, and argued that the measurement of service quality should provide an analysis of the system to achieve a given level of quality of health care (the characteristics of physicians, hospitals and employees); of the process (interaction with the structure) and of the outcome (what happens to the patient after the medical act) [24].

Studies have revealed that a patient's satisfaction is affected by the therapeutic relationship between the doctor and the patient, the therapeutic efficacy and the patient's health-related quality of life [25]; the doctor's technical skills and the quality of information given to the patient, the hospital environment, the quality of infrastructure and support 
services, patient's previous experiences and the cost of services as well as the fulfillment of his needs and his expectations [26-30].

Particularly, understanding patients' expectations and perceptions of the provided services is a key element of the assessment of quality [31] and can be measured by comparing the above two dimensions [32,33]. If the services provided are more than their expectations, those services are considered excellent [33]. A difference between the two does not necessarily indicate low-quality service, but rather that the patient requirements have not been met, which lead to his/her dissatisfaction [34].

The main aim of this study was to investigate patients' perceptions and expectations regarding the quality of health services offered by the 5 public hospitals under study. Additional objectives were to evaluate the gap of each dimension, to determine whether the sociodemographic factors influence it and to highlight which dimension is the most important for patients.

\section{Materials and Methods}

\subsection{The SERVQUAL Quality Questionnaire}

The SERVQUAL-The Service Quality Questionnaire [35] is a methodology and at the same time a tool for analysis, development and measurement of service quality at the functional rather than technical level [36]. Its creators emphasize that there are several factors that are commonly important to all services and, most significantly, are crucial to determining quality [34]. Parasuraman, Berry and Zeithaml defined the quality of service as the difference between the expected service and the perceived service.

Initially, they had proposed 10 dimensions of services quality. Subsequently, they concluded at 5 dimensions that included 22-items. The dimensions are defined as follows: $[35,37]$

“Tangibles: physical facilities, equipment and appearance of personnel. Reliability: ability to perform the service accurately and dependably. Responsiveness: willingness to help customers and provide prompt service. Assurance: employees' knowledge, courtesy and ability to convey trust and confidence. Empathy: caring and individualized attention provided to customers".

Despite the fact that the method has received negative reviews from various academics [6,34], SERVQUAL measurement is the most popular scale used to evaluate service quality [38] including hospitals worldwide [39] and in Greece too [6,34,40].

\subsection{Participants and Procedure}

The survey was carried out in 5 public general hospitals in the Region of Attica, Greece. The selection criterion for these hospitals was the large number of patients they frequently treated and accommodated. According to the Greek Ministry of Health [41], the Attica region has 23 General Public Hospitals that provided health services to 634,691 patients in 2019. In the same year, the five hospitals we studied provided health care services to 172,968 patients (27 percent of the whole access population). Secondary and tertiary care, as well as advanced primary care, are all offered by the specific hospitals.

The research design was a cross-sectional analysis and the sampling technique used was convenience sampling. This is a non-probability sampling method where the sample is taken from a group of patients easy to contact or reach (i.e., those who were more willing to participate in the survey). The 700 valid filled-in questionnaires corresponded to a response rate of $70 \%$.

The participants of the research were adults (over 18 years), patients who understood and spoke fluently the Greek language and patients not hospitalized with covid-19. The research was conducted from the 7 November 2020 to the 31 December 2020.

All participants were provided with a written consent form, by means of a declaration, as a separate part of the questionnaire, before proceeding with the completion of the survey. Data collection guaranteed anonymity and confidentiality. All subjects were informed 
of their right to refuse or discontinue participation in the study, according to the ethical standards of the Helsinki Declaration.

\subsection{Research Instrument}

The research method used in this study for data collection was the Greek version of the SERVQUAL Quality Questionnaire which had been validated for Greek health settings by Christoglou, Vassiliadis and Sigalas [40]. It consists of 22 pairs of questions [expectations (E) and perceptions $(\mathrm{P})$ ] that make up the five quality dimensions. The dimensions are the following: (i) Tangibles (4 items); (ii) Reliability (5 items); (iii) Responsiveness (4 items); (iv) Assurance (4 items); (v) Empathy (5 items). All the questions were ranked on a 7-point Likert scale, ranging from 1-totally disagree to 7-totally agree, which means that higher scores show higher expectations and better evaluation of the received services. The questionnaire had two more sections, both of which were parts of the original research tool: one regarding the demographic characteristics of the respondents ( 5 items) and another one where the patients were asked to allocate a total of 100 points among the five quality dimensions considering how important each dimension was to them.

\subsection{Statistical Analysis}

Data analysis was carried out with SPSS 26 (IBM, Athens, Greece). The five quality dimensions were calculated as mean values of the variables/questions that composed each one of them. This was done for both expectations and perceptions and thus ten new variables (five pairs of perceptions-expectations for each service quality dimension) were created. Afterwards, the gap between perceptions and expectations was calculated for these variables by subtracting expectations from perceptions [P-E]. Kolmogorov-Smirnov and Shapiro-Wilk tests were applied to assess normality of their distributions. These tests showed a statistically significant deviation from normality. Additionally, their graphical illustration using boxplots displayed many outliers for all the gaps, thus all the statistical tests that were used were non-parametric (Table 1).

Table 1. Normality tests for SERVQUAL dimensions.

\begin{tabular}{ccccccc}
\hline \multicolumn{7}{c}{ Tests of Normality } \\
\hline & \multicolumn{7}{c}{ Kolmogorov-Smirnov $^{\text {a }}$} & \multicolumn{3}{c}{ Shapiro-Wilk } \\
\cline { 2 - 7 } & Statistic & df & Sig. & Statistic & df & Sig. \\
\hline GT & 0.119 & 700 & 0.000 & 0.963 & 700 & 0.000 \\
GRel & 0.127 & 700 & 0.000 & 0.932 & 700 & 0.000 \\
GRes & 0.128 & 700 & 0.000 & 0.941 & 700 & 0.000 \\
GA & 0.125 & 700 & 0.000 & 0.937 & 700 & 0.000 \\
GE & 0.116 & 700 & 0.000 & 0.937 & 700 & 0.000 \\
\hline
\end{tabular}

a Lilliefors Significance Correction. GT: Gap Tangibles, GRel: Gap Reliability, GRes: Gap Responsiveness, GA: Gap Assurance, GE: Gap Empathy.

Specifically, the non-parametric Mann-Whitney U test was used to determine possible statistically significant differences of the gaps between two independent groups and Kruskal-Wallis $\mathrm{H}$ test was used to determine whether statistically significant differences existed between more than two groups (with post-hoc analysis based on the non-parametric Dunn's test with Bonferroni correction). Additionally, Wilcoxon matched-pairs signedranks test was used to check for statistically significant differences between perceptions and expectations for each of the five pairs of the quality dimensions and the non-parametric Spearman's Rho correlation coefficient was used in order to evaluate for possible correlations between the gaps of perceptions-expectations of the SERVQUAL dimensions.

Regarding the reliability of the questionnaire, Cronbach's alpha coefficient was calculated separately for each section of the questionnaire which composed the quality subscales, for both expectations and perceptions. Its values ranged between 0.68 and 0.88 , [Tangibles: $(E)=0.76,(P)=0.80$, Reliability: $(E)=0.86,(P)=0.88$, Responsiveness: $(E)=0.68$, 
$(P)=0.85$, Assurance: $(E)=0.87,(P)=0.80)$ and Empathy: $(E)=0.83,(P)=0.88]$ and they are considered to be good to excellent. This result was a proof of the questionnaire's internal consistency. The level of statistical significance was set to $\alpha=0.05$.

\section{Results}

\subsection{Descriptive Analysis of the Sample}

The SERVQUAL questionnaire was distributed to 1000 patients of 5 Greek Public Hospitals in the region of Attica and 700 valid questionnaires were returned. A summary of the demographic characteristics of the participants is shown in Table 2. Specifically, $59.3 \%$ of the respondents received clinical hospitalization (ClHos) and $40.7 \%$ of them were treated in outpatient clinics (OutCl). From 700 respondents, $50.6 \%$ were males and $49.4 \%$ were females. Regarding the age distribution, most of the respondents $(29.4 \%)$ belonged to the age group of (50-64), $26.1 \%$ belonged to the age group of (35-49), $22.4 \%$ to the age group of (65 and over) and the remaining $22.0 \%$ to the age group of (18-34). In terms of education level, the majority of the participants $(36.6 \%)$ were university graduates (UG) with or without a postgraduate degree, $33.6 \%$ and $14.5 \%$ of them reported that they were secondary (SE) and postsecondary education (PSE) graduates respectively, while $15.3 \%$ had completed compulsory education (CE). Finally, regarding their marital status, the majority $(47.3 \%)$ of the participants reported that they were married (Table 2).

Table 2. Demographic characteristics of the respondents $(n=700)$ and evaluation of the impact of demographic characteristics on SERQUAL dimensions.

\begin{tabular}{|c|c|c|c|c|c|c|c|c|}
\hline & & & & Tangibles & Reliability & Responsiveness & Assurance & Empathy \\
\hline & & Frequency & Percent & $\begin{array}{c}\text { Test } \\
p \text {-Value }\end{array}$ & $\begin{array}{c}\text { Test } \\
p \text {-Value }\end{array}$ & $\begin{array}{c}\text { Test } \\
p \text {-Value }\end{array}$ & $\begin{array}{c}\text { Test } \\
p \text {-Value }\end{array}$ & $\begin{array}{c}\text { Test } \\
p \text {-Value }\end{array}$ \\
\hline \multirow{2}{*}{$\begin{array}{l}\text { Type of } \\
\text { service }\end{array}$} & OutCl + & 285 & 40.7 & \multirow{2}{*}{$\begin{array}{c}\mathrm{U}^{*}=56,425.50 \\
p=0.300\end{array}$} & \multirow{2}{*}{$\begin{array}{c}\mathrm{U}^{*}=47,382.50 \\
p<0.001\end{array}$} & \multirow{2}{*}{$\begin{array}{c}\mathrm{U}^{*}=49,536.00 \\
p<0.001\end{array}$} & \multirow{2}{*}{$\begin{array}{c}\mathrm{U}^{*}=51,448.50 \\
p=0.003\end{array}$} & \multirow{2}{*}{$\begin{array}{c}\mathrm{U}^{*}=49,519.50 \\
p<0.001\end{array}$} \\
\hline & $\mathrm{ClHos}++$ & 415 & 59.3 & & & & & \\
\hline \multirow{2}{*}{ Gender } & Male & 354 & 50.6 & \multirow{2}{*}{$\begin{array}{c}\mathrm{U}^{*}=56,125.00 \\
p=0.055\end{array}$} & \multirow{2}{*}{$\begin{array}{c}\mathrm{U}^{*}=57,029.00 \\
p=0.113\end{array}$} & \multirow{2}{*}{$\begin{array}{c}\mathrm{U}^{*}=59,713.00 \\
p=0.565\end{array}$} & \multirow{2}{*}{$\begin{array}{c}\mathrm{U}^{*}=57,659.00 \\
p=0.178\end{array}$} & \multirow{2}{*}{$\begin{array}{c}\mathrm{U}^{*}=57,492.00 \\
p=0.159\end{array}$} \\
\hline & Female & 346 & 49.4 & & & & & \\
\hline \multirow{4}{*}{$\begin{array}{l}\text { Age } \\
\text { Groups }\end{array}$} & $18-34$ & 154 & 22.0 & \multirow{4}{*}{$\begin{array}{c}\mathrm{H}^{* *}=9.94 \\
p=0.02\end{array}$} & \multirow{4}{*}{$\begin{array}{c}\mathrm{H}^{* *}=30.02 \\
p<0.001\end{array}$} & \multirow{4}{*}{$\begin{array}{c}\mathrm{H}^{* *}=5.53 \\
p=0.137\end{array}$} & \multirow{4}{*}{$\begin{array}{c}\mathrm{H}^{* *}=17.40 \\
p=0.001\end{array}$} & \multirow{4}{*}{$\begin{array}{c}\mathrm{H}^{* *}=10.57 \\
p=0.014\end{array}$} \\
\hline & $35-49$ & 183 & 26.1 & & & & & \\
\hline & $50-64$ & 206 & 29.4 & & & & & \\
\hline & 65 and over & 157 & 22.4 & & & & & \\
\hline \multirow{4}{*}{$\begin{array}{c}\text { Education } \\
\text { level }\end{array}$} & $\mathrm{CE}^{\wedge}$ & 107 & 15.3 & \multirow{4}{*}{$\begin{array}{c}\mathrm{H}^{* *}=13.43 \\
p=0.004\end{array}$} & \multirow{4}{*}{$\begin{array}{c}\mathrm{H}^{* *}=15.83 \\
p=0.001\end{array}$} & \multirow{4}{*}{$\begin{array}{c}\mathrm{H}^{* *}=3.40 \\
p=0.334\end{array}$} & \multirow{4}{*}{$\begin{array}{c}\mathrm{H}^{* *}=11.81 \\
p=0.008\end{array}$} & \multirow{4}{*}{$\begin{array}{c}\mathrm{H}^{* *}=11.47 \\
p=0.009\end{array}$} \\
\hline & $\mathrm{SE}^{\wedge}$ & 235 & 33.6 & & & & & \\
\hline & $\mathrm{PSE}^{\wedge \wedge}$ & 102 & 14.5 & & & & & \\
\hline & $\mathrm{HE}^{\wedge \mu \wedge}$ & 256 & 36.6 & & & & & \\
\hline \multirow{4}{*}{$\begin{array}{l}\text { Marital } \\
\text { status }\end{array}$} & Single & 205 & 29.3 & \multirow{4}{*}{$\begin{array}{c}\mathrm{H}^{* *}=6.29 \\
p=0.098\end{array}$} & \multirow{4}{*}{$\begin{array}{c}\mathrm{H}^{* *}=18.10 \\
p<0.001\end{array}$} & \multirow{4}{*}{$\begin{array}{c}\mathrm{H}^{* *}=6.28 \\
p=0.09\end{array}$} & \multirow{4}{*}{$\begin{array}{c}\mathrm{H}^{* *}=13.09 \\
p=0.004\end{array}$} & \multirow{4}{*}{$\begin{array}{c}\mathrm{H}^{* *}=6.37 \\
p=0.095\end{array}$} \\
\hline & Married & 331 & 47.3 & & & & & \\
\hline & Divorced & 98 & 14.0 & & & & & \\
\hline & Widow & 66 & 9.4 & & & & & \\
\hline
\end{tabular}

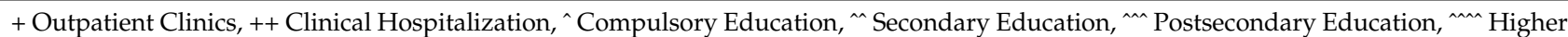
Education, * Mann-Whitney U test, ${ }^{* *}$ Kruskal-Wallis H test.

\subsection{Gap Analysis}

The gaps for the SERVQUAL dimensions were calculated by subtracting expectations from perceptions [P-E] and their values would specify the overall quality of the health services as assessed by the participants. Further, a mean quality gap was calculated for each dimension as a mean value of the gaps of the questions/items that composed each one of them. A negative value of the gap indicated that the quality of the provided services was lower than expected, while a positive gap value indicated higher-quality services than expected. 
The following table (Table 3) shows that the gaps for all the dimensions of quality had a negative value, which means that the provided health services were lower than expected for all the dimensions. The Tangibles dimension was the one with the highest gap score $(-0.92)$, followed by Assurance ( -0.81$)$ and by Empathy $(-0.72)$, while Responsiveness was the dimension with the lowest gap score $(-0.62)$ followed by Reliability $(-0.70)$, which means that the last two were the dimensions where the difference between perceptions and expectations was the smallest. It should be noted at this point that the overall mean gap was negative and of particular interest is the finding that none of the items had a positive gap.

Table 3. Results for Expectations, demographic characteristics of the respondents by quality Dimension.

\begin{tabular}{|c|c|c|c|c|}
\hline & Question/Item & Expectations & Perceptions & Gap \\
\hline \multirow{5}{*}{ Tangibles } & Hospital should have up-to-date equipment & 6.74 & 5.51 & -1.23 \\
\hline & $\begin{array}{l}\text { The facilities of the hospital (e.g., waiting room/hall, clinics, } \\
\text { wards, toilets) should be visually appealing }\end{array}$ & 6.49 & 5.10 & -1.39 \\
\hline & The hospital staff should be well dressed and appear neat & 6.62 & 6.14 & -0.48 \\
\hline & $\begin{array}{l}\text { The equipment used for treatment should always be well } \\
\text { maintained }\end{array}$ & 6.82 & 6.25 & -0.57 \\
\hline & Mean Value & 6.67 & 5.75 & -0.92 \\
\hline \multirow{6}{*}{ Reliability } & $\begin{array}{c}\text { When hospital staff promise to do something by a certain } \\
\text { time, they should do it }\end{array}$ & 6.59 & 5.83 & -0.76 \\
\hline & $\begin{array}{c}\text { When a patient has a problem, hospital staff should be } \\
\text { willing to help him/her }\end{array}$ & 6.68 & 6.04 & -0.64 \\
\hline & $\begin{array}{c}\text { Hospital should be reliable and always provide the right } \\
\text { services from the beginning }\end{array}$ & 6.77 & 6.02 & -0.75 \\
\hline & $\begin{array}{c}\text { Hospital should provide its service at the time it promises to } \\
\text { do so }\end{array}$ & 6.65 & 5.89 & -0.76 \\
\hline & $\begin{array}{l}\text { Hospital should keep their records accurately (e.g., medical } \\
\text { record, appointments, etc.) }\end{array}$ & 6.76 & 6.19 & -0.57 \\
\hline & Mean Value & 6.69 & 5.99 & -0.70 \\
\hline \multirow{5}{*}{ Responsiveness } & Hospital staff should keep the patient informed & 6.69 & 6.00 & -0.69 \\
\hline & Hospital staff should provide prompt services to patients & 6.61 & 5.77 & -0.84 \\
\hline & Hospital staff should always be willing to help patients & 6.72 & 6.09 & -0.63 \\
\hline & $\begin{array}{l}\text { The staff of the hospital should always respond to patients' } \\
\text { requests, no matter how busy they are }\end{array}$ & 6.00 & 5.68 & -0.32 \\
\hline & Mean Value & 6.51 & 5.89 & -0.62 \\
\hline \multirow{5}{*}{ Assurance } & $\begin{array}{l}\text { The behavior and attitude of hospital staff should inspire } \\
\text { confidence in patients }\end{array}$ & 6.74 & 6.14 & -0.60 \\
\hline & I should feel safe in my dealings with the hospital staff & 6.72 & 6.12 & -0.60 \\
\hline & Hospital staff should be consistent and polite to the patients & 6.70 & 6.07 & -0.63 \\
\hline & $\begin{array}{l}\text { Hospital staff should receive adequate support in order to } \\
\text { do their job well }\end{array}$ & 6.75 & 5.34 & -1.41 \\
\hline & Mean Value & 6.73 & 5.92 & -0.81 \\
\hline \multirow{6}{*}{ Empathy } & Hospital staff should pay special attention to each patient & 6.57 & 5.94 & -0.63 \\
\hline & $\begin{array}{l}\text { The operation hours of the hospital should be convenient for } \\
\text { all patients }\end{array}$ & 6.40 & 5.60 & -0.80 \\
\hline & $\begin{array}{l}\text { Hospital staff should understand and have the knowledge of } \\
\text { the health needs of their patients }\end{array}$ & 6.61 & 5.95 & -0.66 \\
\hline & Hospital should have in mind the interests of their patients & 6.53 & 5.76 & -0.77 \\
\hline & $\begin{array}{l}\text { Hospital staff should understand the specific health needs of } \\
\text { their patients }\end{array}$ & 6.67 & 5.93 & -0.74 \\
\hline & Mean Value & 6.56 & 5.84 & -0.72 \\
\hline & Total Mean Gap & & & -0.75 \\
\hline
\end{tabular}

In regard to the patients' expectations, Table 3 shows that Assurance was the dimension with the highest score (6.73) followed by the dimensions of Reliability (6.69), Tangibles 
(6.67), Empathy (6.56) and Responsiveness (6.51). While, in terms of patients' perceptions, in Table 3 it is shown that the dimension with the highest value was Reliability (5.99), followed by Assurance (5.92), Responsiveness (5.89), Empathy (5.84) and Tangibles (5.75).

The five statements with the highest and the lowest scores on expectations are presented in Table 4. These are the services for which patients expect the highest and the lowest level of quality respectively. It can be seen that four out of five statements with the highest scores concern the dimensions of reliability and assurance and one concerns the tangibles dimension. This finding indicated that patients place more importance on the reliability and assurance of health services than on tangibles, responsiveness and empathy. Nevertheless, they considered the hygiene of the instruments of high importance. The above findings are also confirmed by the fact that three out of five statements with the lowest scores were concerned the empathy dimension, and the other two concerned tangibles and responsiveness. However, it is worth mentioning that among the five statements with the lowest scores on perceptions, the item with the highest score belonged to the responsiveness dimension.

Table 4. Statements with the highest and lowest scores on Expectations.

\begin{tabular}{cc}
\hline & Expectations-Highest Scores \\
\hline Item/Statement & Scores \\
The equipment used for treatment should always be well maintained & 6.82 \\
Hospitals should be reliable and always provide the right services from the beginning. & 6.77 \\
Hospitals should keep their records accurately (e.g., medical record, appointments, etc.) & 6.76 \\
Hospital staff need to receive adequate support in order to do their job well. & 6.75 \\
The behavior and attitude of hospital staff should inspire confidence in patients. & 6.74 \\
Expectations-Lowest Scores & 6.00 \\
The staff of the hospital should always respond to patients' requests, no matter how busy they are. \\
The operation hours of the hospitals should be convenient for all patients. \\
Hospitals should have in mind the interests of their patients. \\
Hospital staff should pay special attention to each patient. \\
6.40 \\
6.49 \\
6.53
\end{tabular}

In terms of patients' perceptions, Table 5 presents the five statements with the highest and the lowest scores respectively. These are the services that patients rated as the best and worst regarding their perceived quality. From Table 5 it is shown that four out of the five statements with the highest scores on perceptions concerned the dimensions of assurance and tangibles and the fifth considered the reliability dimension. In particular, one of the items of assurance and one of the items of tangibles dimensions were also among the five statements with the highest scores in expectations and the same holds for the item of the reliability dimension. These statements were: "The behavior and attitude of hospital staff should inspire confidence in patients", "The tools they use for my treatment are always neat and clean" and "The hospital keeps its records properly (e.g., Medical Record, Appointments, etc.)" (Tables 4 and 5).

Regarding the statements with the lowest scores on perceptions, two out of five concerned the tangibles dimension and the remaining three concern the dimensions of assurance, responsiveness and empathy. It is worth noting that the item of the assurance dimension was also among the five statements with the highest scores in expectations. This item as well as the two items of the tangibles dimension were the only ones with a gap greater than -1.00 . 
Table 5. Statements with the highest and lowest scores on Perceptions.

Perceptions-Highest Scores
Item/Statement
The equipment they use for my treatment are always well maintained
The hospital staff is well dressed and neat appears.
The hospital keeps its records accurately (e.g., medical record, appointments, etc.)
The behavior and attitude of the hospital staff inspires confidence in patients.
Perceptions-Lowest Scores
6.19
6.14
6.14
6.12
The staff of the hospital always responds to the requests of the patients, no matter how busy they are
The operation hours of the hospital are convenient for all patients.
Hospital has up-to-date equipment.
The employees of the hospital receive the appropriate support in order to do their job well
The facilities of the hospital (e.g., waiting room/hall, clinics, wards, toilets) were visually appealing.

\subsubsection{Analysis of the Difference in Perceptions-Expectations}

A Wilcoxon matched-pairs signed-ranks test was used to assess whether there were significant differences between expectations and perceptions of the patients for the five service quality dimensions. Tests proved to be significant $(p<0.001)$ for the pairs of perceptions-expectations of all the dimensions. This result indicates that the median perceptions' scores were statistically significantly lower that the median expectations' scores for all the dimensions (Table 6).

Table 6. Summary of differences between Expectations-Perceptions for the SERVQUAL dimensions (Wilcoxon matched pairs signed ranks test).

\begin{tabular}{ccccc}
\hline & z-Value & $p$-Value & Median Perceptions & Median Expectations \\
\hline Tangibles: Perceptions-Expectations & -18.098 & $<0.001$ & 6.00 & 7.00 \\
Reliability: Perceptions-Expectations & -12.129 & $<0.001$ & 6.20 & 7.00 \\
Responsiveness: Perceptions-Expectations & -14.065 & $<0.001$ & 6.00 & 6.75 \\
Assurance: Perceptions-Expectations & -17.783 & $<0.001$ & 6.00 & 7.00 \\
Empathy: Perceptions-Expectations & -16.167 & $<0.001$ & 6.00 & 6.80 \\
\hline
\end{tabular}

\subsubsection{Gaps Correlations}

Statistical analysis with Spearman's Rho correlation showed statistically significant $(p<0.01)$ strong positive correlations (Table 7) among all the gaps of perceptions-expectations of the SERVQUAL dimensions, apart from the correlations between the gaps of: (i) tangibles-responsiveness and (ii) tangibles-empathy, which are significant, positive and moderate ( 0.543 and 0.573 respectively). From the same table it was also noticed that the strongest correlations were observed between: (i) the gaps of reliability and responsiveness (0.743), (ii) the gaps of reliability and assurance (0.734) and (iii) the gaps of assurance and empathy dimensions (0.710).

Table 7. Spearman's Rho correlation coefficients among the gaps of perceptions-expectations of the SERVQUAL dimensions $(n=700)$.

\begin{tabular}{cccccc}
\hline & GT & GRel & GRes & GA & GE \\
\hline GT & 1.000 & $0.637^{* *}$ & $0.543^{* *}$ & $0.619^{* *}$ & $0.573^{* *}$ \\
GRel & & 1.000 & $0.743^{* *}$ & $0.734^{* *}$ & $0.677^{* *}$ \\
GRes & & & 1.000 & $0.693^{* *}$ & $0.690^{* *}$ \\
GA & & & & 1.000 & $0.710^{* *}$ \\
GE & & & & & 1.000 \\
${ }^{* *} p<0.01$ & & & &
\end{tabular}




\subsection{Impact of Sociodemographic Factors on Gap}

3.3.1. Type of Service Factor

The non-parametric Mann-Whitney U test was used to evaluate the impact of "Type of Service" on the gaps of perceptions-expectations for the dimensions of SERVQUAL. The test was statistically significant for all the gaps except for the one of tangibles dimension, $(\mathrm{UGT}=56,425.50, p=0.300, \mathrm{UGRel}=47,382.50, p<0.001$, UGRes $=49,536.00, p<0.001$, $\mathrm{UGA}=51,448.50, p=0.003$, UGE $=49,519.50, p<0.001$ ) (Table 2). Additionally, the test indicated that the gaps of all the dimensions were statistically significantly smaller for the patients who received clinical hospitalization than for those who were treated in outpatient clinics (GRel: MedianOutCl $=0.6 \mathrm{MedianClHos}=0.4$, GRes: MedianOutCl $=0.5$ MedianClHos $=0.25$, GA: MedianOutCl $=0.75$ MedianClHos $=0.5$, GE: MedianOutCl $=0.6$ MedianClHos $=0.4$ ).

\subsubsection{Gender Factor}

The gender factor did not seem to affect patients' perceptions as regarding the quality of health services, since Mann-Whitney U test was not statistically significant for any of the gaps of perceptions-expectations of the SERVQUAL dimensions (UGT $=56,125.00 p=0.055$, UGRel $=57,029.00, p=0.113$, UGRes $=59,713.00, p=0.565$. UGA $=57,659.00, p=0.178$, $\mathrm{UGE}=57,492.00, p=0.159)($ Table 2$)$.

\subsubsection{Age Groups Factor}

Regarding the "Age Groups" factor, statistical analysis using the Kruskal-Wallis H test showed statistically significant differences among the age groups for all the gaps of SERVQUAL dimensions apart from the responsiveness one (HGT $=9.94, p=0.02$, HGRel $=30.02, p<0.001$, HRes $=5.53, p=0.137$, HGA $=17.40, p=0.001$, HGE $=10.57$, $p=0.014$ ) (Table 2). The subsequent post hoc analysis for the gaps, based on the Dunn's test adjusted with Bonferroni correction, identified that statistically significant differences exist for: (i) Tangibles Gap for the pair [(65 and over) vs. (18-34)], [ $p=0.02$, median (65 and over $=1.0$, median $(18-34)=0.5)]$, (ii) Reliability Gap for the pairs: (a) [(65 and over) vs. $(18-34)],[p<0.001$, median (65 and over) $=0.2$, median $(18-34)=0.8)],(b)[(65$ and over $)$ vs. (35-49)], $[p=0.003$, median (65 and over) $=0.2$, median (35-49) $=0.6)]$ and (c) $[(50-64)$ vs. $(18-34)]$, $[p=0.002$, median $(50-64)=0.4$, median $(18-34)=0.8)]$, (iii) Assurance Gap for the pairs: (a) [(65 and over) vs. (18-34)], $[p=0.001$, median ( 65 and over) $=0.5$, median $(18-34)=1.0]$, and (b) [(65 and over) vs. (35-49)], [ $p=0.01$, median (65 and over) $=0.5$, median (35-49) $=0.75$, and finally (iv) Empathy Gap for the pair [(65 and over) vs. (18-34)], $[p=0.01$, median $(65$-over $)=0.2$, median $(18-34)=0.8)]$. It can be seen that older patients had significant smaller gaps than the younger patients for all the dimensions except for responsiveness, where the test was not statistically significant.

\subsubsection{Marital Status Factor}

Based on the analysis with Kruskal-Wallis $\mathrm{H}$, in order to study the impact of "Marital Status" factor on the gaps of perceptions-expectations of SERVQUAL dimensions, the test proved to be statistically significant only for the gaps of reliability and assurance dimensions $(\mathrm{HGT}=6.29, p=0.098$, HGRel $=18.10, p<0.001$, HRes $=6.28, p=0.099$, HGA $=13.09, p=0.004$, HGE $=6.37, p=0.095)($ Table 2$)$.

The subsequent post hoc analysis for the gaps, based on the Dunn's test adjusted with Bonferroni correction, proved statistically significant differences for: (i) Reliability Gap- or the pairs: (a) [widow vs single], $[p<0.029$, median (widow) $=0.2$, median $($ single $)=0.8$ ) and (b) [married vs single], $[p<0.002$, median (married) $=0.4$, median $($ single $)=0.8)]$ and (ii) Assurance Gap for the pair [married vs single], [ $p<0.048$, median (married) $=0.5$, median $($ single $)=0.75)$ ]. It can be observed that the gaps of the unmarried patients were larger than those of married patients and widows as regards reliability and the assurance dimension. 


\subsubsection{Education Level Factor}

The non-parametric Kruskal Wallis-H test, was used to evaluate the impact of "Education Level" on the gaps of SERVQUAL dimensions. The test was statistically significant for all the gaps except for the gap of responsiveness (HGT $=13.43, p=0.004$, HGRel $=15.83$, $p=0.001$, HRes $=3.40, p=0.334$, HGA $=11.81, p=0.008$, HGE $=11.47, p=0.009)$ (Table 2).

From the post hoc analysis, it was shown that statistically significant differences exist for: (i) Tangibles Gap-for the pairs (a) [CE vs. HE)], $[p=0.005$, median (CE) $=0.5$, median $(\mathrm{HE})=1.0)]$ and b) [SE vs. HE)], $[p=0.04$, median $(\mathrm{SE})=0.75$, median $(\mathrm{HE})=1.0)]$, (ii) Reliability Gap-for the pairs: (a) [CE vs. HE)], $[p=0.003$, median (CE) $=0.2$, median $(\mathrm{HE})=0.8)]$ and (b) $[\mathrm{SE}$ vs HE) $],[p=0.013$, median $(\mathrm{SE})=0.4$, median $(\mathrm{HE})=0.8$ (iii) Assurance Gap-for the pairs: (a) [CE vs. HE)], $[p=0.032$, median (CE) $=0.5$, median $(\mathrm{HE})=0.75)]$ and (b) [SE vs. HE) $],[p=0.028$, median $(\mathrm{SE})=0.5$, median $(\mathrm{HE})=0.75$ and (iv) Empathy Gap-only for the pair [CE vs. HE)], $[p=0.023$, median $(\mathrm{CE})=0.2$, median $(\mathrm{HE})=0.6)]$.

\subsubsection{Patients' Prioritization of Quality Dimensions}

As it is mentioned in the third section of the questionnaire, patients were asked to allocate a total of 100 points among the five quality dimensions considering how important each dimension was to them. The allocation of the points had to be done in such a way that the highest score was to be allocated to the most important dimension, the lowest score was to be allocated to the least important dimension, and the sum of all scores had to be equal to 100. According to patients, the five quality dimensions were ranked from the most important to the least as follows: (1) Assurance (23.48), (2) Reliability (22.70), (3) Responsiveness (19.08), (4) Empathy (17.90), and (5) Tangibles (16.84) as it is shown in Table 8 and in Figure 1.

Table 8. Prioritization of quality dimensions.

\begin{tabular}{|c|c|c|}
\hline Dimension & Question & Points \\
\hline Tangibles & $\begin{array}{l}\text { Visually appealing of physical facilities, } \\
\text { equipment and hospital's employees }\end{array}$ & 16.84 \\
\hline Reliability & $\begin{array}{l}\text { Ability of the hospital to execute promising } \\
\text { services with reliability and accuracy }\end{array}$ & 22.70 \\
\hline Responsiveness & $\begin{array}{l}\text { Hospital staff willingness to provide help } \\
\text { to patients }\end{array}$ & 19.08 \\
\hline Assurance & $\begin{array}{l}\text { Hospital staff with knowledge, good manners and } \\
\text { inspiring confidence }\end{array}$ & 23.48 \\
\hline \multirow[t]{2}{*}{ Empathy } & $\begin{array}{l}\text { Provision of individual interest and attention to } \\
\text { patients by hospital's employees }\end{array}$ & 17.90 \\
\hline & Total & 100 \\
\hline
\end{tabular}




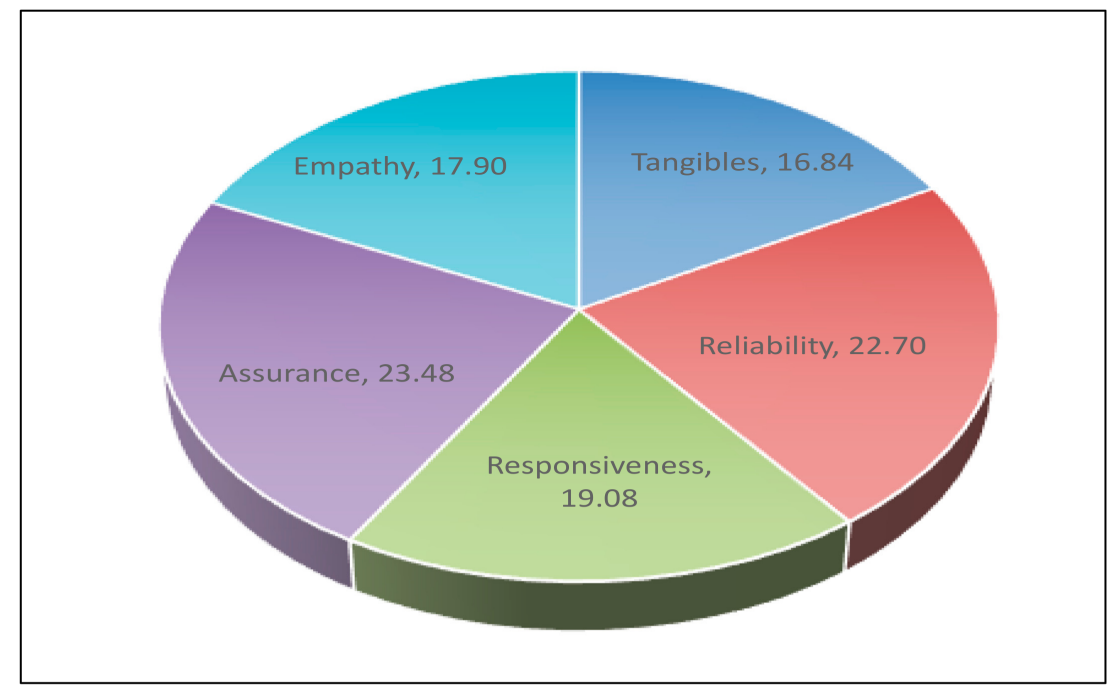

Figure 1. Prioritization of quality dimensions.

\section{Discussion}

Researching and analyzing the opinion of patients-users is considered as one of the most important indicators for evaluating health services' provided quality. It is a key administrative element that has been taken into account in most health care system reforms. It is considered as a means of feedback on the health system from society, which in its discretion, strengthens the problem identification and resolution, identifies the most cost-effective management techniques and therefore contributes to the implementation of programs that continuously improve the quality of health services [42,43].

In this study, 700 patients from 5 general hospitals in the region of Attica participated, aiming to assess the hospitals' quality. The research tool used was the Greek version of SERVQUAL [40]. It consists of 22 pairs of questions (expectations and perceptions) that make up five quality dimensions.

Overall, by this study, it was made clear that patients' expectations as regards the quality of the provided services are not met. All of the five quality dimensions have a negative gap between patients' expectations and perceptions. This finding is similar to most of the studies using the SERVQUAL instrument in Greece $[4,34]$, as well as in other countries [44-52].

Concerning the Greek public hospitals, a few studies highlighted that one reason for this negative gap is the economic crisis that the country has been undergoing for more than 10 years. Even nowadays, there are still shortages in supplies, facilities and staff with unfavorable consequences on the quality of the provided hospital care. Furthermore, the reduction in the number of employees, the drastic cuts in wages and the abolition of the thirteenth monthly wage, due to the crisis, tend to have increased job dissatisfaction, which can indirectly lead to poor job results, absenteeism and low effort [53-56].

Although the gap scores for SERVQUAL were all negative, it is important not to jump to a negative conclusion about the services offered. In fact, the perception assessment scores that were recorded for hospitals were above the neutral value of " 4 ", for all the dimensions. These scores were cancelled out by higher expectation scores resulting in negative gap scores [33].

Regarding the quality dimensions of the instrument, the highest gap appeared in the tangibles dimension (-0.92). This result was in line with the studies of Arasli et al. [52] and Ahmad et al. [48], but disagreed with the findings of the studies of Fan et al. [47], and Purcarea et al. [38]. The patients participated in our study seemed to be the least satisfied with the physical environment, the equipment, the hygienic conditions, the hospital cleanliness and the appearance of health employees. According to Karrasavidou et al. [6], tangibles is the easiest quality dimension for patients to evaluate since they do 
not have the knowledge and the expertise to question the doctors' decision about their health problems. A comfortable and appealing physical environment, up-to-date and well-maintained equipment, a clean environment and an attractive employee appearance help patients to relax and deal better with their anxieties. If these parameters are absent, it is highly possible for a patient to feel dissatisfied.

Apart from the tangible dimension, there were negative gaps in the other dimensions as well. Specifically, these gaps in descending order were: assurance ( -0.81$)$, empathy $(-0.72)$, reliability $(-0.70)$ and responsiveness $(-0.62)$. These dimensions mainly refer to the interpersonal relationships [57], transactions and contacts that patients have with health care professionals. According to Babakus and Mangold [58], negative gaps in these dimensions are a sign of deeper underlying problems in the quality of hospitals. As Papanikolaou and Zygiaris have mentioned, "low scores in the above dimensions may reflect the inability of the service to hire and retain high-quality professionals, evaluate or reward performance or provide adequate training" [34].

These four dimensions reflect the patients-health care employees' relationship and particularly the doctor-patient relationship. This is a relationship that mainly focuses on physicians' expertise, experience and ability to help a patient [6]. Most of the time patients act and judge emotionally. They observe if doctors are genuinely concerned for their patients, if they respond to them appropriately and if they are able to assist them [59]. The doctor-patient relationship is an essential element in patient satisfaction [60]. Felleti et al. have shown that this relationship can predict patient satisfaction and in particular explains $24 \%$ of variability of it [61].

Concerning these four quality dimensions, the findings of the present study were similar to other studies carried out in in Greece [34]. It seems that health care professionals have little time to provide sympathy and reassurance, to pay individualized attention to patients, to inspire confidence or to make patients to feel safe.

These findings were further supported by analyzing the patients' responses to the question of which quality dimension they considered as the most important for assessing the overall quality of the provided health services. According to their answers, the most important dimension was assurance followed by reliability, responsiveness and empathy. This classification of dimensions was consistent with the results of other surveys both nationally and internationally [40,44,45].

In fact, this finding highlights the impact that health care professionals, and especially doctors, have on patients' assessment of quality and it is a notification from patients to health care professionals. Patients seek out health care professionals/doctors with a real interest in patients' problems and a willingness to try to solve them, who are constantly informed, courteous, to promote a sense of trust and security, without complaining about the workload, who manage their time rationally and who understand the specific needs of each patient. Practically, patients want to be at the center of the health care system [6,40].

The dimension of tangibles in this study, as in most of the studies, emerged as the least important for assessing the health services' quality $[4,45,62]$.

It's worth mentioning that the results of the present study indicated that when patients' expectations in one dimension were not met, they might not be met in other dimensions as well, particularly when the correlations were strong. The same result was reached by Manulik S et al. [63]. Inadequacy in one of the dimensions that was particularly important to the patients would almost certainly lead to lower ratings in the others. This result showed that quality was a holistic and indivisible concept. Although it could be described by a set of dimensions with different aspects of it, in its core, it remained inseparable.

In this point, it is worth mentioning that in our sample the number of in-patients was much higher than the number of outpatients, which is not the usual situation. This was due to the covid-19 pandemic crisis, where fewer outpatients were visiting hospitals on a daily basis as they were concerned about the virus, and also because hospitals' policies were prohibiting outpatient visits. Regarding gender, the result was similar to other studies 
and indicated that the perceived quality gap did not differ between female and male participants [34,64].

In relation to age, the results indicated that older patients had a better opinion of the quality of health services than the younger ones and the result was in line with other studies $[34,65]$. An empirical analysis in 31 countries concluded that the older a patient is, the more pleased they tend to be with a country's healthcare system [66]. One possible explanation of this result is that older people, due to their old age, pay more visits to the hospitals and therefore they have more previous experience. In future research, it will be important to investigate further this finding and learn how prior perceptions influence the perceived quality of a specific health service.

Concerning marital status, the unmarried patients considered the quality of services worse compared to married patients and to widow ones. The result was similar to other studies as well [34].

Referring to educational level, the patients with a higher educational level had larger gaps than patients with lower educational level, which also means that they had a worse perception on the quality of services for those dimensions. The literature stated that the level of patient education is an important factor in the perception of quality. In particular, people with low level of education have lower expectations and thus state that they are more satisfied with the doctor-patient relationship, the hospital's facilities and equipment. This may be due to their limited knowledge and inability to judge the services provided. In contrast, highly educated people report lower satisfaction as they expect more [34,67].

\section{Limitations of Study}

This study has some limitations. Firstly, the sampling technique used was convenience sampling, which introduced a systematic selection error and did not allow the results to be generalized. Further, the findings of the survey referred to five general hospitals in Attica, so the results can only be generalized to these hospitals and may not reflect the patients' expectations and perceptions regarding the quality of public health services offered in the region. Future qualitative research that will thoroughly examine the role of personality-related variables or the state of patients' health and the type of the disease entity in determining health quality expectations would benefit in more accurate results.

\section{Conclusions}

This study made an attempt, by using the SERVQUAL instrument, to evaluate patients' expectations and perceptions regarding the quality of offered public health services. The findings suggested that hospital managers and health care professionals should be more concerned about patient expectations and should find ways and approaches to fulfill them. Open communication with patients, individualized attention, sensitivity to their requirements, polite behavior, a trustful atmosphere across the hospital and better physical facilities are the key elements that determine the patient's judgment about quality. The results of our research were similar to those of other surveys $[6,34,40]$ conducted 10 or 15 years ago and essentially before the economic crisis in the country. The human aspect quality gap was found to be the most critical area for development, and consequently an indicator of overall service quality assessment. Consequently, the health care quality could be systematically measured and hospital managers could take into account the results of these measurements, aiming at the development of policies that will upgrade the quality of health care services. Moreover, health policy makers need to reconsider and foster a public dialogue on the health budget, which could be regarded as a developmental tool rather than a financial burden, with an emphasis not only on the economic development but also on the wellbeing of people.

Author Contributions: Conceptualization, A.G. (Aspasia Goula); Methodology, A.G. (Aspasia Goula), M.-A.S., M.K. and E.K.; Software, M.-A.S., M.A., L.V., A.G. (Aristeidis Galanakis), G.T., E.S.; Validation, M.-A.S.; Formal analysis, M.-A.S., A.G. (Aspasia Goula), M.K. and E.K.; Investigation, A.G. (Aspasia Goula), M.-A.S., M.A., L.V., A.G. (Aristeidis Galanakis), G.T., E.S., M.K., and 
E.K.; Resources, A.G. (Aspasia Goula) and M.-A.S.; Data curation, A.G. (Aspasia Goula), M.-A.S., M.K. and E.K.; Writing-Original Draft Preparation, A.G. (Aspasia Goula), M.-A.S., M.K. and E.K.; Writing-Review and Editing, A.G. (Aspasia Goula), M.-A.S., M.K. and E.K.; Visualization, A.G. (Aspasia Goula); Supervision, A.G. (Aspasia Goula); Project administration, A.G. (Aspasia Goula). All authors have read and agreed to the published version of the manuscript.

Funding: This research received no external funding.

Institutional Review Board Statement: Research ethical approval from the Research Ethics Committee of the five hospitals was obtained (protocol numbers: 16-06/10/2020, 20733-16/10/2020, 3463-02/11/2020, 21-13/10/2020, and 319-13/10/2020).

Informed Consent Statement: Informed consent was obtained from all subjects involved in the study.

Data Availability Statement: Restrictions apply to the availability of these data. Data were collected from Post-Graduate Program "Health and Social Care Management" of the Department of Business Administration of the University of West Attica and are available from Goula A. with the permission of MSc Program.

Acknowledgments: This study has been done within the framework of the Postgraduate Health and Social Care Management Programme of the University of West Attica.

Conflicts of Interest: The authors declare no conflict of interest.

\section{References}

1. Economou, C.; Kaitelidou, D.; Karanikolos, M.; Maresso, A. Greece: Health System Review. Health Systems in Transition; European Observatory of Health Systems and Policy, World Health Organization: London, UK, 2017; Volume 19, pp. 1-192. Available online: https:/ / eclass.uoa.gr/modules/document/file.php/NURS338/\%CE\%9A\%CE\%B5\%CE\%AF\%CE\%BC\%CE\%B5\%CE\% BD\%CE\%B1/Economou\%20t\%20al_Health\%20Systems\%20in\%20Transition_Greece_Health\%20system\%20review_2017.pdf (accessed on 10 January 2021).

2. Tountas, Y. The Health of Greeks in Economic Crisis; Institute of Social and Preventive Medicine: Athens, Greece, 2016. Available online: https://www.dianeosis.org/wp-content/uploads/2016/03/ygeia_singles_complete_ver02.pdf (accessed on 18 March 2021).

3. OECD; European Union. Health at a Glance: Europe 2020: State of Health in the EU Cycle; OECD Publishing: Paris, France, 2020. [CrossRef]

4. Soulis, S. Applied Social Policy; Papazizis Publications: Athens, Greece, 2016; pp. 660-668.

5. Valentine, N.B.; De Silva, A.; Kawabata, K.; Darby, C.; Murray, C.J.L.; Evans, D.B. Health system responsiveness: Concepts, domains and operationalization. In Health Systems Performance Assessment: Debates, Methods and Empiricism; Murray, C.J.L., Evans, D.B., Eds.; World Health Organization: Geneva, Switzerland, 2003; pp. 573-596.

6. Karassavidou, E.; Glaveli, N.; Papadopoulos, C.T. Quality in NHS hospitals: No one knows better than patients. Meas. Bus. Excell. 2009, 13, 34-46. [CrossRef]

7. European Commission. Patient Safety and Quality of Healthcare: Full Report; Office of the European Union-Directorate-General for Communication: Brussels, Belgium, 2010. Available online: https://ec.europa.eu/commfrontoffice/publicopinion/archives/ ebs/ebs_327_en.pdf (accessed on 16 January 2021).

8. European Commission. Patient Safety and Quality of Healthcare: Report; Office of the European Union-Directorate-General for Health and Consumers: Luxembourg, 2014. Available online: https:/ / ec.europa.eu/commfrontoffice/publicopinion/archives/ ebs/ebs_411_en.pdf (accessed on 16 January 2021).

9. Mixalopoulos, N. From Public Bureaucracy to Public Management; Papazisis Publications: Athens, Greece, 2003 ; pp. $235-239$.

10. Tountas, $\Upsilon$. Quality issues in medical practice and in health services. Arch. Hell. Med. 2003, 20, 532-546. Available online: http: / / www.mednet.gr/archives/2003-5/pdf/532.pdf (accessed on 20 January 2021).

11. Jabnoun, N.; Al Rasasi, A.J. Transformational leadership and service quality in UAE hospitals. Manag. Serv. Qual. 2005, 15, 70-81. [CrossRef]

12. Jun, M.; Peterson, R.T.; Zsidisin, G.A. The identification and measurement of quality dimensions in the health care: Focus group interview results. Health Care Manag. Rev. 1998, 23, 81-96. Available online: https://journals.lww.com/hcmrjournal/Fulltext/19 98/10000/The_Identification_and_Measurement_of_Quality.7.aspx (accessed on 15 December 2020). [CrossRef] [PubMed]

13. Spreng, R.A.; MacKenzie, S.B.; Olshavsky, R.W. A re-examination of the determinants of consumer satisfaction. J. Mark. 1996, 60, 15-32. [CrossRef]

14. Reichheld, F.; Sasser, W. Zero defections: Quality comes to service. Harv. Bus. Rev. 1990, 68, 106-107. [PubMed]

15. Gronroos, C. A service quality model and its marketing implications. Eur. J. Mark. 1984, 18, 36-44. [CrossRef]

16. Parasuraman, A.; Zeithaml, V.A.; Berry, L.L. A conceptual model of service quality and its implications for future research. $J$. Mark. 1985, 49, 41-50. [CrossRef] 
17. Kano, N.; Seraku, N.; Takahashi, F.; Tsuji, S. Attractive quality and must-be quality. J. Jpn. Soc. Qual. Control 1984, $14,39-48$. [CrossRef]

18. Sarris, M. Health Sociology and Quality of Life; Papazisis Publications: Athens, Greece, 2001; p. 289.

19. Dosen, D.O.; Skare, V.; Cerfalvi, V.; Bencekovic, Z.; Komaracv, T. Assessment of the quality of public hospital healthcare services by using SERVQUAL. Acta Clin. Croat. 2020, 59, 285-293. [CrossRef]

20. Institute of Medicine. Medicare: A Strategy for Quality Assurance; Lohr, K.N., Ed.; National Academy Press: Washington, DC, USA, 1990; Volume I-II, p. 21.

21. Pierrakos, G.; Yiovannis, A.; Latou, D.; Goula, A.; Pateras, J.; Sarris, M. Measurement of the satisfaction in Greece outpatients departments of public hospitals. In Proceedings of the 4th International Conference in Quantitative and Qualitative Methodologies in the Economic and Administrative Sciences (I.C.Q.Q.M.E.A.S.), Athens, Greece, 21-22 May 2015; pp. 301-307.

22. Ryan, M.; Scott, D.A.; Reeves, C.; Bate, A.; Van Teijlingen, E.R.; Russell, E.M.; Napper, M.; Robb, C.M. Eliciting public preferences for healthcare: A systematic review of techniques. Health Technol. Assess 2001, 5, 1-186. [CrossRef]

23. Olsen, J.A.; Smith, R.D. Theory versus practice: A review of "willingness-to-pay" in health and health care. Health Econ. 2001, 10, 39-52. [CrossRef]

24. Giovanis, A.; Pierrakos, G.; Kyriakidou, N.; Yfantopoulos, J.; Goula, A.; Latsou, D.; Tomaras, P.; Sarris, M. Service quality asymmetric effect on patient satisfaction for primary healthcare services. The Future of Entrepreneurship. In Proceedings of the 7th Annual EuroMed Conference of the EuroMed, 18-19 September 2014; Academy of Business: Kristiansand, Norway, 2014; pp. 669-682. Available online: https:/ / core.ac.uk/download/pdf/30267203.pdf (accessed on 2 January 2021).

25. Sarris, M.; Goula, A. Patients' Quality of Life as a Measurement of Health Care Services Quality; Papazisis: Athens, Greece, 2006; pp. 325-333.

26. Greeneich, D.S.; Long, C.O.; Miller, B.K. Patient satisfaction update: Research applied to practice. Appl. Nurs. Res. 1992, 5, 43-48. [CrossRef]

27. Meterko, M.; Nelson, E.C.; Rubin, H.R.; Batalden, P.; Berwick, D.M.; Hays, R.D.; Ware, J.E. Patient judgments of hospital quality: Report of a pilot study. Med. Care 1990, 28, 1-56. Available online: https://www.jstor.org/stable/3765180 (accessed on 15 November 2020). [CrossRef] [PubMed]

28. Risser, N.L. Development of an instrument to measure patient satisfaction with nurses and nursing care in primary care settings. Nurs. Res. 1975, 24, 45-52. [CrossRef] [PubMed]

29. Linder-Pelz, S. Social psychological determinants of patient satisfaction: A test of five hypotheses. Soc. Sci. Med. 1982, 16, 583-589. [CrossRef]

30. Fenton, J.J.; Jerant, A.F.; Bertakis, K.D.; Franks, P. The cost of satisfaction: A national study of patient satisfaction, health care utilization, expenditures, and mortality. Arch. Intern. Med. 2012, 172, 405-411. [CrossRef] [PubMed]

31. Parasuraman, A.; Zeithaml, V.A.; Berry, L.L. Refinement and reassessment of the SERVQUAL scale. J. Retail. 1991, 67, 420-450.

32. Speigth, J. Assessing Patient Satisfaction: Concepts, Applications and Measurement. Value Health 2005, 8, 6-8. [CrossRef] [PubMed]

33. Anbari, Z.; Tabaraie, Y. Measurement of quality of hospital services via SERVQUAL Model. Bull. Environ. Pharmacol. Life Sci. 2013, 3, 51-56. Available online: http:/ / bepls.com/dec2013/11.pdf (accessed on 20 November 2020).

34. Papanikolaou, V.; Zygiaris, S. Service quality perceptions in primary health care centers in Greece. Health Expect 2012, 17, 197-207. [CrossRef] [PubMed]

35. Parasuraman, A.; Zeithaml, V.A.; Berry, L.L. SERVQUAL: A multiple-item scale for measuring consumer perceptions of service quality. J. Retail. 1988, 64, 12-40.

36. Teshnizi, S.H.; Aghamolaei, T.; Kahnouji, K.; Tesnizi, S.M.H.; Chani, J. Assessing quality of health services with the SERVQUAL model in Iran. A systematic review and meta-analysis. Int. J. Qual. Health Care 2018, 30, 82-89. [CrossRef]

37. Ramya, N.; Kowsalya, A.; Dharanipriya, K. Service quality and its dimensions. EPRA Int. J. Res. Dev. 2019, 4, 38-41. Available online: https: / / www.researchgate.net/publication/333058377_SERVICE_QUALITY_AND_ITS_DIMENSIONS (accessed on 1 December 2020).

38. Purcarea, V.L.; Gheorghea, I.R.; Petrescu, C.M. The assessment of perceived service quality of public health care services in Romania using the SERVQUAL Scale. Procedia Econ. Financ. 2013, 6, 573-585. [CrossRef]

39. Li, M.; Lowrie, D.B.; Huang, C.Y.; Lu, X.C.; Zhu, Y.C.; Wu, X.H.; Shayiti, M. Quality at hospitals in nine Chinese cities by use of the ServQual scale. Asian Pac. J. Trop. Biomed. 2015, 5, 497-504. [CrossRef]

40. Christoglou, K.; Vassiliadis, C.; Sigalas, I. Using SERVQUAL and Kano research techniques in a patient service quality survey. World Hosp. Health Serv. 2006, 42, 21-26. [PubMed]

41. Ministry of Health. Hospitalized Beds-Days of Hospitalization 2019. Available online: https://www.moh.gov.gr/articles/ bihealth/stoixeia-noshleytikhs-kinhshs (accessed on 16 February 2019).

42. Ford, R.C.; Bach, S.A.; Fottler, M.D. Methods of measuring patient satisfaction in health organizations. Health Care Manag. Rev. 1997, 22, 74-89. [CrossRef] [PubMed]

43. Goula, A.; Sarris, M.; Pierrakos, G.; Sryropoulos, N.; Vourliotou, K.; Nikolados, I. The added value of patient satisfaction measurements. Arch. Hell. Med. 2017, 34, 49-57. Available online: http://www.mednet.gr/archives/2017-1/pdf/49.pdf (accessed on 25 November 2020). 
44. Anderson, E.A.; Zwelling, L. Measuring service quality at the University of Texas M.D. Anderson Cancer Center. Int. J. Health Care Qual. Assur. 1996, 9, 9-22. [CrossRef]

45. Sewell, N. Continuous quality improvement in acute health care: Creating a holistic and integrated approach. Int. J. Health Care Qual. Assur. 1997, 1, 20-26. [CrossRef]

46. Gholami, M.; Kavosi, Z.; Khojastefar, M. Services quality in emergency department of Nemazee hospital: Using SERVQUAL model. J. Health Man. Inf. 2016, 3, 120-126.

47. Fan, L.H.; Gao, L.; Liu, X.; Zhao, S.H.; Mu, H.T.; Li, Z.; Shi, L.; Wang, L.L.; Jia, X.L.; Ha, M.; et al. Patients' perceptions of service quality in China: An investigation using the SERVQUAL model. PLoS ONE 2017, 12, e0190123. [CrossRef]

48. Ahmad, B.Z.; Mohd, I.I.; Anees, A.H. Level of satisfaction on service quality dimensions based on SERVQUAL model among patients attending Malaysia clinic in Kota Bharu. Oman. Med. J. 2018, 33, 416-422. [CrossRef]

49. Brahmbhatt, M.; Baser, N.; Joshi, N. Adapting the SERVQUAL scale to hospital services: An empirical investigation of patients' perceptions of service quality. Int. J. Multidiscip. Res. 2011, 1, 27-42. Available online: http:/ /www.zenithresearch.org.in/images/ stories/pdf/2011/Dec/zijmr/2_VOL\%201_ISSUE8_ZEN.pdf (accessed on 15 January 2021).

50. Essiam, J.O. Service quality and patient satisfaction with healthcare delivery: Empirical evidence from patients of the outpatient department of a public university hospital in Ghana. Eur. J. Bus. Manag. 2013, 5, 52-59. Available online: https: //www.iiste.org/Journals/index.php/EJBM/article/view/8718/9004 (accessed on 3 February 2021).

51. Isik, O.; Tengilimoglu, D.; Akbolat, M. Measuring health care quality with the SERVQUAL method: A comparison in public and private hospitals. Health Med. 2011, 5, 1921-1930.

52. Arasli, H. Gearing service quality into public and private hospitals in small islands. Empirical evidence from Cyprus. Int. J. Health Care Qual. Assur. 2008, 21, 8-23. [CrossRef]

53. Keramidou, I.; Triantafyllopoulos, L. The impact of the financial crisis and austerity policies on the service quality of public hospitals in Greece. Health Policy 2018, 122, 352-358. [CrossRef]

54. Simou, E.; Koutsogeorgou, E. Effects of the economic crisis on health and healthcare in Greece in the literature from 2009 to 2013: A systematic review. Health Policy 2014, 115, 111-119. [CrossRef] [PubMed]

55. Aiken, L.H.; Sermeus, W.; Vanden Heede, K.; Sloane, D.M.; Busse, R.; McKee, M. Patient safety, satisfaction, and quality of hospital care: Cross sectional surveys of nurses and patients in 12 countries in Europe and the United States. BMJ 2012, 344, e1717. [CrossRef]

56. Kalafati, M. How Greek healthcare services are affected by the Eurocrisis. Emerg. Nurse 2012, 20, 26-27. [CrossRef]

57. Manulik, S.; Rosińczuk, H.; Karniej, P. Evaluation of health care service quality in Poland with the use of SERVQUAL method at the specialist ambulatory health care center. Patient Prefer. Adherence 2016, 10, 1435-1442. [CrossRef]

58. Babakus, E.; Mangold, W.G. Adapting the SERVQUAL scale to hospital services: An empirical investigation. Health Serv. Res. 1992, 26, 767-786.

59. Azmi, T.; Rahman, H.; Mustafi, M.A.A.; Islam, R. Measurement of Patient Satisfaction with SERVQUAL Model of Private Hospitals: SEM Approach. Am. J. Manag. 2017, 17, 64-76.

60. Inui, T.S.; Carter, W.B.; Kukull, W.A.; Haigh, V.H. Outcome-based doctor-patient interaction analysis: I. Comparison of techniques. Med. Care 1982, 20, 535-549. Available online: https://www.jstor.org/stable/3764165? seq=1 (accessed on 3 February 2021). [CrossRef] [PubMed]

61. Feletti, G.; Firman, D.; Sanson-Fisher, R.S. Patient satisfaction with primary-care consultations. J. Behav. Med. 1986, 9, 389-399. [CrossRef] [PubMed]

62. Kalaja, R.; Myshketa, R.; Scalera, F. Service quality in health care sector: The case of Durres public hospital. Procedia Soc. Behav. Sci. 2016, 235, 557-565. [CrossRef]

63. Shaikh, B.T.; Mobeen, N.; Azam, S.I.; Rabbani, F. Using SERVQUAL for assessing and improving patient satisfaction at a rural health facility in Pakistan. East Mediterr. Health J. 2008, 14, 447-456. Available online: https://pubmed.ncbi.nlm.nih.gov/185617 38/ (accessed on 5 February 2021).

64. Karavida, A.; Stamouli, M.A.; Balis, C. Patients' satisfaction evaluation with the health center of Elis Province. Stud. Health Technol. Inform. 2014, 202, 283-286. [PubMed]

65. Xesfingi, S.; Vozikis, A. Patient satisfaction with the healthcare system: Assessing the impact of socio-economic and healthcare provision factors. BMC Health Serv. Res. 2016, 16, 94. [CrossRef] [PubMed]

66. Alrubaiee, L.; Alkaaida, F. The mediating effect of patient satisfaction in the patients' perceptions of healthcare quality-patient trust relationship. Int. J. Mark. Stud. 2011, 3, 103-127. [CrossRef]

67. Lumby, J.; England, K. Patient satisfaction with nursing care in a colorectal surgical population. Int. J. Nurs. Pract. 2000, 6, 140-145. [CrossRef] [PubMed] 